\title{
AN EVALUATION OF WATER QUALITY INDEX VARIATION IN DOMESTIC DRINKING WATER RESERVOIRS
}

\author{
Abubakar Bilyaminu Musa ${ }^{1}$, Mala Babagana Gutti ${ }^{2}$ \\ ${ }^{I}$ Shelter Program Officer, Shelter Program Sector, Mercy Corps, Maiduguri, Nigeria. \\ ${ }^{2}$ B.Eng. Graduate, Department of Civil and Water Resources Engineering, University of Maiduguri, \\ Maiduguri, Nigeria. \\ ABSTRACT
}

\begin{abstract}
This study investigates the variation in water quality parameters due to short term storage in reservoirs in northeast Nigeria. The objective of the study is to determine the water quality, testing selected vital parameters and determining the DWQI of the samples from selected water sources and their respective reservoirs. The World Health Organization (WHO), as well as the Canadian Council of Ministers of the Environment (CCME) standards of water quality test and drinking water quality indices, were adopted. Samples were collected at both source and reservoir from five different points in the same area. The quality of water was analyzed in order to determine the variation in water quality and drinking water quality indices when stored over time in a storage system. The result of the quality test revealed that the level of all the parameters were within the limit set by WHO except that of Iron and Manganese which were slightly above the standard limits. The correlated variables revealed that a very strong relationship exists between all the samples with the highest $R^{2}$ as 0.99 and the lowest $R^{2}$ as 0.94 . The drinking water quality indices were found to be good for all samples with an index value of $88.45 \%$. This study strongly recommends further investigation as well as regular monitoring of the drinking water quality in the area.
\end{abstract}

Keywords: - Water quality assessment, Drinking water quality, Drinking water, Drinking water quality index, WHO, Water reservoirs, Groundwater quality.

\subsection{INTRODUCTION}

The quality of drinking water has a huge impact on our health and hence, effective monitoring and assessment of drinking water systems are important to the protection of the wellbeing of the public [1]. Such monitoring allows the implementation of a preventive approach to manage drinking water quality [3-4]. The lack of enough good water will threaten our survival since only $0.6 \%$ of water exists as groundwater which is the only source of good water [1]. Water is highly essential to our health and economy as well as for the survival of all living organisms [2]. Freshwater is a significant need for human life thus, the quality of drinking water is a concern that is crucial since it is directly linked with public health [2]. Monitoring the quality of drinking water is an important component of water management as it will help in the identification of problems [3]. Health problems may occur due to poor quality of drinking water, therefore, drinking water quality should meet the standards and be free from chemical elements in high concentrations that affect health and also from pathogenic microorganisms [5]. Although parameters of drinking water quality may vary based on countries, most countries have zero tolerance for these parameters since the body needs pure water for drinking [6]. It will be of importance if regular water quality assessment will be carried out on both domestic and public water sources, supply channels and storage systems as that will provide water quality information for treatment and other necessary actions. 


\subsection{MATERIALS AND METHODS}

\subsection{Study Area}

The study was conducted at Bolori area of Maiduguri, Nigeria situated along $11^{0} 51^{\prime} \mathrm{N} 13^{\circ} 08^{\prime} \mathrm{E}$. It is a residential as well as a commercial area with most of the population as middle to low-class citizens with family sizes ranging between 5 and 15 individuals with groundwater as the main source of drinking water. Water storage in a reservoir is the most practiced among the people residing in the area due to frequent power shortage with an average of 5 days storage period in the reservoirs, with the sizes of reservoir ranging between 2000-5000 Liters.

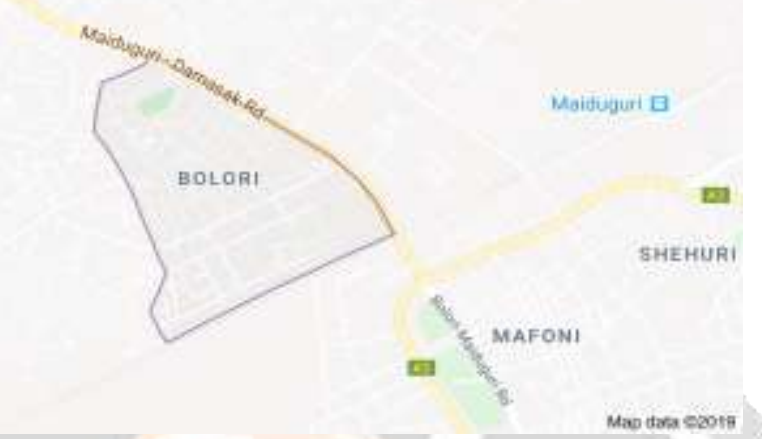

Fig-1: Map of the Study Area.

\subsection{Sample Collection and Analysis}

A total of 10 samples were collected from 5 different locations. Samples were collected in clean, sterile containers from both sources and storage reservoirs. All the collected samples were stored in an icebox with proper aseptic technique and transported to the laboratory immediately for the experimental analysis. The level of total coliform, $\mathrm{pH}$, Zinc, Iron, Manganese and Lead were determined.

\subsection{RESULTS AND DISCUSSION}

\subsection{Variation of Water Quality Parameters}

Table-1: Water Quality Data

\begin{tabular}{|l|c|c|c|c|c|c|c|c|c|c|}
\hline \multirow{2}{*}{ Parameters } & \multicolumn{9}{|c|}{ Source } & \multicolumn{5}{c|}{ Reservoir } \\
\cline { 2 - 12 } & S1 & S2 & S3 & S4 & S5 & R1 & R2 & R3 & R4 & R5 \\
\hline Total Coliform CFU/100mL & NP & 0.00 & 0.00 & 0.00 & 0.00 & 0.00 & 0.00 & 0.00 & 0.00 & 0.00 \\
\hline pH & NP & 6.8 & 7.5 & 6.6 & 6.8 & 6.9 & 6.4 & 6.2 & 6.7 & 6.4 \\
\hline Zinc $(\mathrm{Zn})$ & NP & 0.47 & 0.55 & 0.79 & 0.89 & 0.40 & 0.98 & 0.25 & 0.33 & 1.32 \\
\hline Iron $(\mathrm{Fe})$ & NP & 0.18 & 0.21 & 0.14 & 0.28 & 0.29 & 0.16 & 0.19 & 0.22 & 0.13 \\
\hline Manganese $(\mathrm{Mn})$ & NP & 0.47 & 0.35 & 0.39 & 0.49 & 0.48 & 0.84 & 0.89 & 0.56 & 0.78 \\
\hline Lead $(\mathrm{Pb})$ & $\mathrm{NP}$ & -0.87 & -0.01 & -1.22 & -0.12 & -1.50 & -0.96 & -0.85 & -0.92 & -1.48 \\
\hline
\end{tabular}




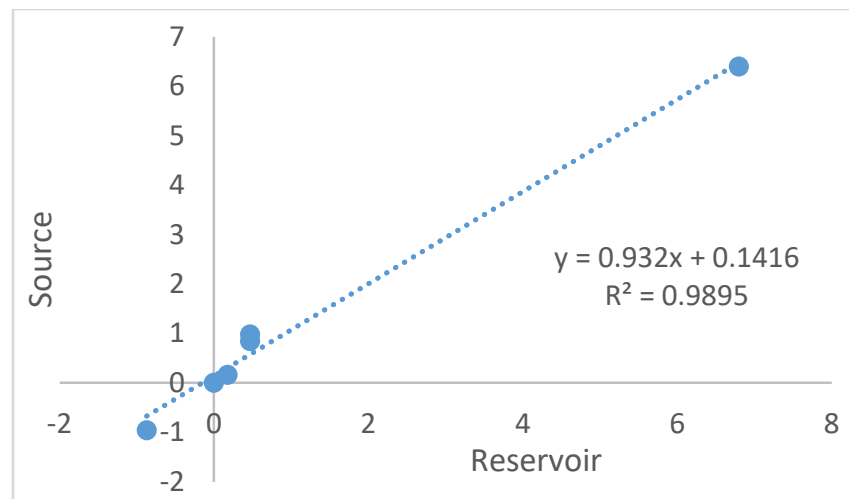

Chart-1: Correlation at Point 2

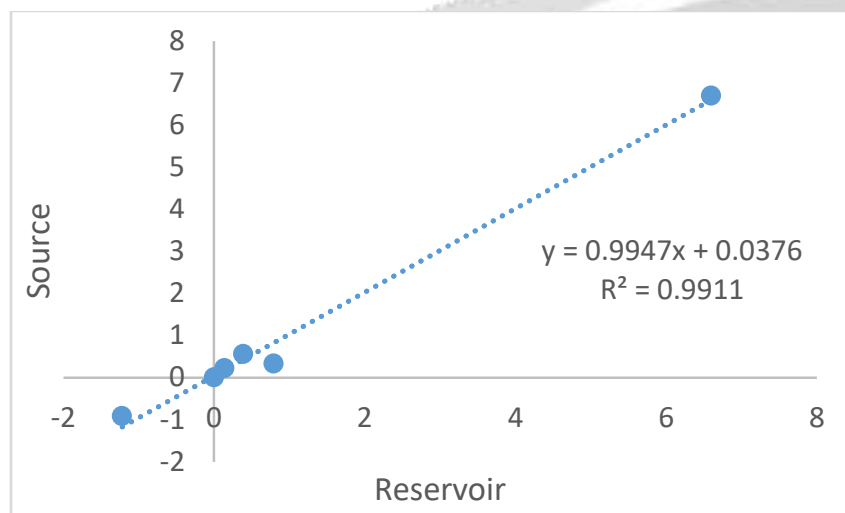

Chart-3: Correlation at Point 4

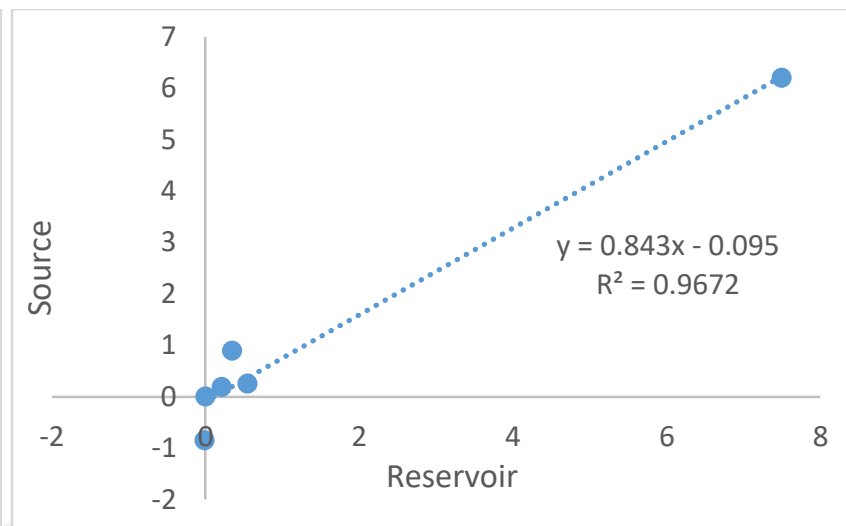

Chart-2: Correlation at Point 3

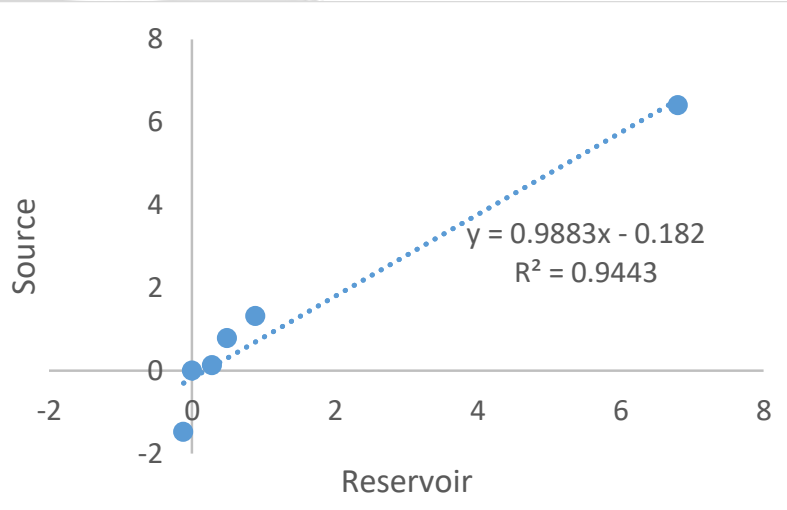

Chart-4: Correlation at Point 5

From Table 1 and Chart 1-4, we can see that total coliforms were not detected in the water samples. The values of $\mathrm{pH}$, Zinc and Lead for the source and reservoir at all points were within the permissible limits set by WHO. The level of Iron and Manganese at all points for both sources and reservoirs were above the limits set by WHO although the variation is slight. The correlated variables at all points showed a very strong relationship between samples with the highest $R^{2}=0.99$ and the lowest as $R^{2}=0.94$. This indicates that the variation in quality between the sources and their respective reservoirs is below $10 \%$ which is just slight. This also means that when low-quality water is collected from the source and stored in a reservoir for a short term, the probability that it will be below the standards is very high.

\subsection{Drinking-Water Quality Index}

In order to assess the drinking water quality index (DWQI), the Canadian Council of Ministers of the Environment (CCME) system was used. These include the measures of variance which are the scope, frequency and amplitude of water quality. According to CCME (2001), the scope represents the water quality of the legal norm of noncompliance during the period of interest and is expressed as

Eq. 1:

$\mathrm{F}_{1}=\left(\frac{\text { No.of Failed Variables }}{\text { Total No.of Variables }}\right) \times 100$

The frequency characterizes the percentage of individual tests that do not meet the objectives Eq. 2 :

$\mathrm{F}_{2}=\left(\frac{\text { No.of Failed Tests }}{\text { Total No.of Tests }}\right) \times 100$

The amplitude represents the amount by which failed tests do not meet the objectives Eq. 3:

$\mathrm{F}_{3}=\left(\frac{n s e}{0.01 \text { nse }+0.01}\right)$ 
Where, nse indicates the normalized sum of excursions or temporal deviations that is the collective amount by which individual tests are out of compliance.

The Drinking Water Quality Index is then calculated as Eq. 4:

DWQI $=100-\left(\frac{\sqrt{F_{1}^{2}+F_{2}^{2}+F_{3}^{2}}}{1.732}\right)$

The index is obtained from a table of reference for the drinking water quality index as seen in Table-2 [7].

Table-2: Drinking Water Quality Index

\begin{tabular}{|c|c|}
\hline DWQI Value & Status \\
\hline $95-100$ & Excellent \\
\hline $89-94$ & Very Good \\
\hline $80-88$ & Good \\
\hline $65-79$ & Fair \\
\hline $45-64$ & Marginal \\
\hline $0-44$ & Poor \\
\hline \multicolumn{2}{|c|}{ Source: CCME, (2001). } \\
\hline
\end{tabular}

Table-3: Drinking water quality index of samples

\begin{tabular}{|c|c|c|}
\hline Sample Point & DWQI Value & Remark \\
\hline S1 & Nil & Nil \\
\hline S2 & 88.45 & Good \\
\hline S3 & 88.45 & Good \\
\hline S4 & 88.45 & Good \\
\hline S5 & 88.45 & Good \\
\hline R1 & 88.45 & Good \\
\hline R2 & 88.45 & Good \\
\hline R3 & 88.45 & Good \\
\hline R4 & 88.45 & Good \\
\hline R5 & 88.45 & Good \\
\hline
\end{tabular}

The drinking water quality index of samples from the sources and reservoirs were good for all the samples as indicated in Table-3. The index 'Good' indicates that the water quality is protected with only a minor degree of impairment; conditions rarely depart from desirable levels.

\subsection{CONCLUSION}

The results obtained conclude that the groundwater used as the source of drinking water in Bolori area is of good physico-chemical quality. The obtained results of the samples were normal when compared to the recommended limits of World Health Organization Standards for physico-chemical, biological and metal analytical parameters. The result of the correlation indicates that a very strong relationship exists between all samples at the sources and reservoirs which show a slight variation. The drinking water quality index of all samples was good which is satisfactory. Therefore, there is a need for a further regular investigation to establish the actual factor responsible for the variation in the quality of drinking water. This will provide information on the actual problems that contributed to the variation in quality by the use of reservoirs to store drinking water.

\section{ACKNOWLEDGEMENT}

The authors acknowledge the assistance from the International Rescue Committee's Environmental Health Laboratory, Maiduguri, Nigeria. 


\section{REFERENCES}

[1] R. Shamsur," Assessment of Drinking Water Quality and Hygienic Conditions of the People Living around the Dingaputha Haor Area of Netrokona District, Bangladesh," Research \& Reviews: Journal of Ecology and Environmental Sciences, 2017, vol. 5, No. 1.

[2] T. A. Prosun, M. S. Rahaman, S. Y. Rikta, and M. A. Rahman, "Drinking water quality assessment from groundwater sources in Noakhali, Bangladesh," International Journal of Development and Sustainability, 2018, vol. 7, No. 5, pp. 1676-1687.

[3] Durmishi, B.H., M. Ismaili, A. Shabani, Sh. Abduli, "Drinking Water Quality Assessment in Tetova Region," Am. J. Environ. Sci., 2012, vol. 8, No. 2, pp. 162-169.

[4] L. Li., P. Byleveld, A. Leask and W. Smith, "Assessment of chemical quality of drinking water in regional New South Wales, Australia," Proceedings of the 18th World IMACS/MODSIM Congress, Cairns, Australia, 2009, pp. 4326-4332.

[5] D. P. Uniyal, J. S. Aswal, V. Chander, R. Dobhal, N. G. Srivastava and K. S. Bari, "Drinking Water Quality Assessment in Schools of Garhwal Region Uttarakhand, India," J. Env. Bio-Sci., 2018, vol. 32, No. 1, pp.153160.

[6] B. Garoma, G. Kenasa, and M. Jida, "Drinking Water Quality Test of Shambu Town (Ethiopia) from Source to Household Taps Using Some Physico-chemical and Biological Parameters," Research \& Reviews: Journal of Ecology and Environmental Sciences, 2018, vol. 6, No. 4.

[7] Canadian Council of Ministers of the Environment (CCME). (2001). "Canadian water quality guidelines for the protection of aquatic life". CCME Water Quality Index 1.0 User's Manual. Published by the Canadian Council of Ministers of the Environment. 